\title{
Cranial computed tomography in the diagnosis of multiple sclerosis
}

\author{
LA LOIZOU, EB ROLFE, H HEWAŻY \\ From the Midland Centre for Neurosurgery and Neurology, Smethwick, and the Departments of Neurology and \\ Radiology, Queen Elizabeth Hospital, Birmingham, UK
}

SUMMARY A group of 202 patients with suspected, probable or definite multiple sclerosis was studied, using cranial computed tomography (CT). Atrophy alone, or in combination with whitematter and periventricular lucencies, and areas of contrast enhancement, were the main abnormal findings in $52 \%$ of patients. Atrophy was detected in $44 \%$ of patients, and its frequency and severity correlated with disease duration up to 10 years, age, and disease category. Atrophic changes in the brainstem and cerebellum could be correlated with clinical data more often than supratentorial atrophy could be correlated with features such as dementia or mood changes. Lucencies in the white matter, thought to represent areas of demyelination, were noted in $21 \%$ of patients, and only a proportion of these lesions could be correlated with clinical data, the others being clinically silent. Contrast enhancement was seen in a small proportion of white-matter lesions, and was independent of disease activity and steroid medication. Electrophysiological tests and cerebrospinal fluid analysis showed a higher yield of abnormality than CT scanning in cases with suspected or possible multiple sclerosis, though in such patients CT scanning excluded alternative cerebral atrophy. Modifications of the technique of CT scanning may improve the detection rate of white-matter lesions, thereby enhancing the value of CT as a diagnostic tool in the study of patients with multiple sclerosis.

Cranial computed tomography (CT) has been used in the investigation of patients with diseases of the white matter, including multiple sclerosis. ${ }^{1-7}$ The main abnormalities detected in CT scans of patients with multiple sclerosis are atrophy and areas of low attenuation, with or without enhancement, interpreted as plaques. The results of the series reported so far have been rather variable, and the diagnostic usefulness of CT has been questioned, especially in the early or suspected cases of multiple sclerosis. The enhancement characteristics of "plaques" have been reported in a small number of patients only, again with variable and conflicting results. The present investigation was undertaken both as a retrospective and prospective assessment of the value of $C T$ in the management of patients with

Address for reprint requests: Dr LA Loizou, Department of Neurology, Pinderfields General Hospital, Aberford Road, Wakefield WF1 4DG, UK.

Received 12 October 1981 and in final revised form 12 May 1982. Accepted 6 June 1982 multiple sclerosis. The various types of abnormality were identified and correlated with the clinical data at the time of CT scanning. The specificity of these abnormalities was assessed, and their usefulness was compared with other standard investigations, namely cerebrospinal fluid analysis, and visual and auditory evoked potentials.

\section{Patients and methods}

All 202 patients in this study had been investigated as inpatients at the neurological units of the Queen Elizabeth Hospital, Birmingham, and the Midland Centre for Neurosurgery and Neurology, between 1977 and 1980. There were 129 female $(63.8 \%)$ and 73 male $(36.2 \%)$ patients, classified on clinical criteria alone into four groups, as described by McDonald and Halliday: ${ }^{8}$ clinically definite (81 patients), probable $(80)$, possible or suspected multiple sclerosis (41). Cerebrospinal fluid (CSF) and electrophysiological results (visual and auditory evoked potentials) were available in most patients, but were not used in the diagnostic criteria. The course of the disease (acute, relapsing, chronic progressive) and its activity at the time of CT scanning (stable, remission, exacerbation) were 
assessed, as described by Hershey et al. ${ }^{5}$ Functional impairment of patients was graded into severe (bedridden or totally dependent), moderate (chairbound or other disability interfering with work and social life), mild, and no impairment.

CT scans were performed using an EMI head-scanner with a $160 \times 160$ matrix (126 patients) or an EMI bodyscanner with a $160 \times 160$ matrix. Fifty-five patients had unenhanced CT scans only; 70 had the CT scan repeated after contrast infusion of $40 \mathrm{ml}$ to $70 \mathrm{ml}$ sodium meglumine diatrazoate (Urografin 370 ); and 77 patients had a postcontrast infusion CT scan only. CT scans were taken initially on polaroid films, but the vast majority were printed on transparencies. CT scans were examined for the presence of atrophic lesions: namely, ventricular dilatation, widening of the sulci and of the basal cisterns with concomitant shrinkage of the brainstem (and cerebellum); an Evans ratio was calculated for each scan as a measure of ventricular size, but this was not found to be as useful as visual inspection in assessing cerebral atrophy. In addition, periventricular and white-matter lesions of low attenuation (PVL and WML) were looked for, and abnormal contrast enhancement noted. No systematic attempt was made to measure whitematter attenuation figures from computer printouts. The CT scans of 325 consecutive patients investigated for complaints such as headache, migraine, vertigo, single seizures, facial neuralgia, possible cerebellopontine angle or pituitary tumour, served as controls. Statistical analysis was carried out using the Student's $t$ test or the $\chi^{2}$ test.

\section{Results}

At the time of CT scanning the age range of the 202 patients with multiple sclerosis was $13-70$ years. The mean age of males in the three disease categories of suspected, probable and definite multiple sclerosis was $40 \cdot 1 \pm 10 \cdot 5,39 \cdot 2 \pm 13 \cdot 6$, and $39 \cdot 5 \pm 11 \cdot 3$ respectively; for females the corresponding figures were $32 \cdot 6 \pm 9 \cdot 4, \quad 42 \pm 12 \cdot 6$, and $42 \cdot 4 \pm 11 \cdot 8$ respectively. Seventy-seven per cent of all patients examined were under 50 years of age, reflecting the age at onset of the disease, as shown in table 1 . In $10 \%$ the age at onset of the disease was before the age of 20 years; in $63 \%$ between 20 and 40 ; and in $27 \%$ between 41 and 70 years. In the possible multiple

Table 1 Age at onset of multiple sclerosis

\begin{tabular}{|c|c|c|c|c|}
\hline \multirow{2}{*}{$\begin{array}{l}\text { Age group } \\
\text { Years }\end{array}$} & \multicolumn{3}{|c|}{ Multiple sclerosis category } & \multirow[t]{2}{*}{ Total } \\
\hline & Possible/Suspected & Probable & Definite & \\
\hline $0-10$ & - & - & 1 & 1 \\
\hline $11-20$ & 3 & 5 & 12 & 20 \\
\hline $21-30$ & 14 & 19 & 28 & 61 \\
\hline $31-40$ & 15 & 23 & 28 & 66 \\
\hline $41-50$ & 5 & 21 & 9 & 35 \\
\hline $51-60$ & 4 & 11 & 3 & 18 \\
\hline $61-70$ & - & & - & 1 \\
\hline Mean \pm SD & $\begin{array}{l}\text { M } 38 \cdot 3 \pm 9 \cdot 56 \\
{ }^{*} \mathrm{~F} 31 \cdot 3 \pm 9 \cdot 53\end{array}$ & $\begin{array}{l}\text { M } 35 \pm 12 \cdot 2 \\
\text { F } 39 \pm 11 \cdot 1\end{array}$ & $\begin{array}{l}\text { M 30.4 } \\
\text { F } 30 \cdot 7 \pm\end{array}$ & $\begin{array}{c}11 \cdot 2 \\
9 \cdot 9\end{array}$ \\
\hline
\end{tabular}

${ }^{*}$ Differs from males, $\mathrm{p}<0.02$. sclerosis group the age at onset was lower in females, the difference being significant $(p<0.02)$. There was no sex difference in the incidence of the disease after the age of 40 . Analysis of the mode of clinical presentation showed that the spinal cord was involved in $72 \%$, the brainstem in $68 \%$, the optic nerves in $33 \%$ and the cerebral hemispheres in $9 \%$ of all patients.

\section{CT SCAN ABNORMALITIES}

CT scan abnormalities consisted of atrophy, periventricular lucencies, lucencies elsewhere in the white matter, and areas of abnormal enhancement (table 2).

\section{(a) Atrophy}

There was an increase in the incidence of atrophy with age, disease category, and disease duration (tables 3 and 4). Supratentorial atrophy alone was present in 31 patients; infratentorial atrophy alone in six patients; while supratentorial and infratentorial atrophy were combined in 51 patients. There was a tendency, therefore, for supratentorial atrophy to be seen more frequently. Sulcal enlargement was present in 78 patients; ventricular dilatation in 59; and brainstem/cerebellar atrophy in 53 patients. Infratentorial atrophy showed correlation with clinical features, for example ataxia, nystagmus and dysarthria, in $72 \%$ of patients, while supratentorial atrophy correlated with features such as memory deficit, and mood changes in only $17 \%$ of patients, the difference being significant $(\mathrm{p}<0 \cdot 001)$ (fig 1$)$.

\section{(b) Periventricular lucencies ( $P V L)$}

Areas of low attenuation in the periventricular region were identified in only 10 patients (two in "probable" and eight in "definite" multiple sclerosis category). Four patients were in exacerbation, and six were in chronic progression of their disease, and none

Table 2 Number of patients showing CT scan abnormalities

\begin{tabular}{lllcr}
\hline CT scan abnormality & \multicolumn{3}{l}{ Multiple sclerosis category } & Total \\
\cline { 2 - 4 } & $\begin{array}{l}\text { Possible/ } \\
\text { Suspected }\end{array}$ & Probable & Definite \\
\hline Atrophy & 4 & 29 & 31 & 64 \\
Atrophy + WML & 0 & 2 & 15 & 17 \\
Atrophy + PVL & 0 & 2 & 3 & 5 \\
Atrophy + PVL + WML & 0 & 0 & 3 & 3 \\
WML & 2 & 6 & $7 \ddagger$ & 15 \\
PVL & 0 & 0 & 1 & 1 \\
Total & 6 & 39 & $60^{*+}$ & 105 \\
\hline
\end{tabular}

$\mathrm{PVL}=$ periventricular luncencies.

WML $=$ white-matter lucencies.

${ }^{*}$ Differs from Possible + Probable groups, $\mathrm{p}<0 \cdot 001$.

+ Differs from Probable, $\mathrm{p}<0 \cdot 01$.

$\ddagger \mathrm{PVL}$ in one patient. 
Table 3 Relationship of atrophic changes to age at $C T$ scanning and category of multiple sclerosis (Number of patients with atrophy expressed as percentage of age group total)

\begin{tabular}{llllll}
\hline $\begin{array}{l}\text { Age group } \\
\text { (years) }\end{array}$ & \multicolumn{2}{l}{ Multiple sclerosis category } & \multicolumn{1}{c}{$\begin{array}{l}\text { Controls } \\
\%\end{array}$} \\
\cline { 2 - 5 } & $\begin{array}{l}\text { Possible) } \\
\text { Suspected } \% \\
\%\end{array}$ & $\begin{array}{l}\text { Probable } \\
\%\end{array}$ & $\begin{array}{l}\text { Definite } \\
\%\end{array}$ & $\begin{array}{l}\text { Total } \\
\%\end{array}$ & \\
\hline $10-20$ & - & 25 & - & $12 \cdot 5$ & 0 \\
$21-30$ & 7 & 6 & 26 & $18 \cdot 6$ & 0 \\
$31-40$ & 6 & 52 & 61 & $43 \cdot 3^{*}$ & 3 \\
$41-50$ & - & 44 & 66 & $53^{*}$ & 12 \\
$51-60$ & 33 & 46 & 75 & $56^{*} \cdot 7^{*}$ & $15 \cdot 6$ \\
$61-70$ & & 83 & 100 & $88 \cdot 8^{\dagger}$ & 44 \\
Total & $9 \cdot 8$ & $41 \cdot 25 \S$ & $62 \cdot 3 \ddagger$ & $44^{*}$ & $10 \cdot 8$ \\
\hline
\end{tabular}

* Differs from controls, $p<0 \cdot 001$.

$\dagger$ Differs from controls, $\mathrm{p}<0.02$.

$\ddagger$ Differs from Probable group, $\mathrm{p}<0 \cdot 01$

$\S$ Differs from Possible group, $p<0.001$

Table 4 Relationship of atrophy to disease duration

$\begin{array}{lcc}\hline \begin{array}{l}\text { Disease duration } \\ \text { (years) }\end{array} & \text { Patients } \\$\cline { 2 - 3 } & \text {$\left.Total } & \begin{array}{l}\text { Percent showing } \\ \text { atrophy }\end{array} \\ \hline 0-5 & 137 & 28 \\ 6-10 & 24 & 62^{*} \\ 11-15 & 11 & 81^{\dagger} \cdot 8^{\dagger} \\ 16-20 & 20 & 75 \\ 21-25 & 6 & 100 \\ 26-30 & 2 & 100 \\ \geq 30 & 2 & 100\end{array}\right\} \neq$

${ }^{*} \mathrm{p}<0.01$ compared to $0-5$ year group.

$\dagger, \ddagger$, not different compared to $6-10$ year group.

showed correlation between clinical data and location of lucencies. PVL were mostly seen in older patients with longer disease duration. Contrast enhancement was not noted. (c) White-matter lucencies and areas of contrast enhancement

White-matter lucencies were seen in two patients with suspected multiple sclerosis, eight patients with probable, and 25 patients with definite multiple sclerosis. Single lucencies were seen in 24 patients; nine patients had two lucencies; one patient showed three lucencies; and another patient showed four lucencies. The location of these lesions was as follows: parietal 15; frontal 11; occipital 10; capsular 7 ; brainstem 3 ; temporal lobe 3 . Only 10 patients showed correlation between location of WML and clinical data (fig 2 ).

Contrast enhancement was noted in white-matter areas in seven patients; in three there were no unenhanced scans for comparison; in the others, low attenuation areas showed uniform or peripheral contrast enhancement; in two of the latter patients, radionuclide scans showed increased uptake of technetium in areas corresponding to the enhancing lesions. There was no correlation between contrast enhancing lesions and disease activity; six patients with enhancing WML were in exacerbation, compared with 15 others who did not show enhancement of their WML. Complete resolution of a contrast-enhancing lesion was noted in one patient.

The incidence of white-matter and/or periventricular lucencies in patients in clinical exacerbation was $23 \%$, compared with $18 \%$ for patients in remission or stable disease activity: the difference is not significant. The incidence of lucencies in patients over the age of 40 was $31 \%$, compared with $13.5 \%$ for patients under the age of 40 , the differences being significant $(p<0 \cdot 01)$. A significant difference $(p<0 \cdot 01)$ was also found in the incidence of WML and PVL in patients with disease duration over five years. In the 56 patients with moderate or severe disability, the incidence of
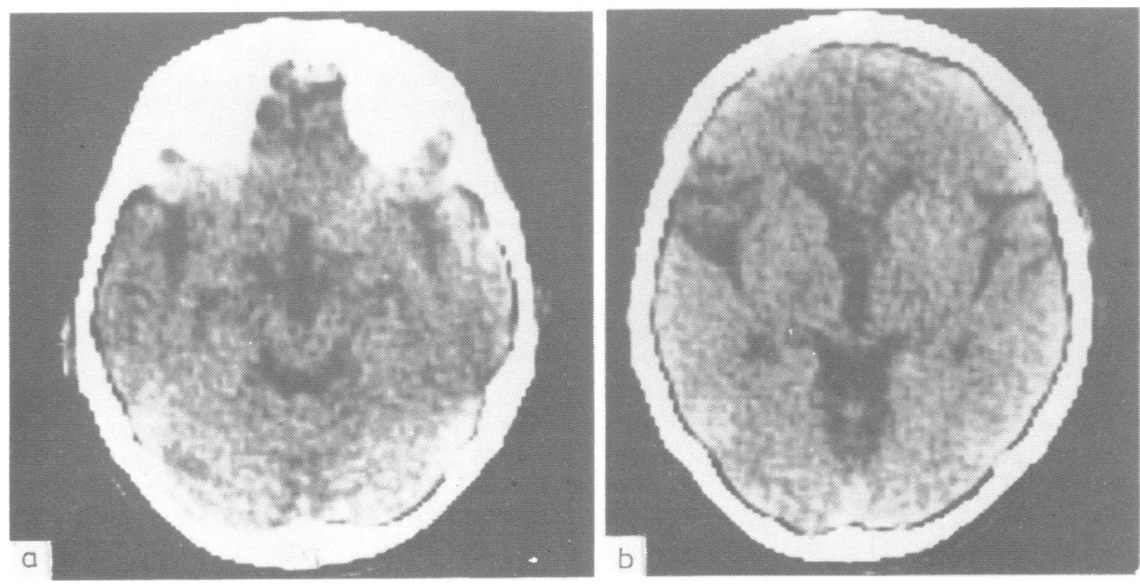

Fig 1a, b Unenhanced scan of a 23-year-old female with a seven-year history of vertigo, unsteadiness and optic pallor, ataxic nystagmus, bilateral limb and trunk ataxia; normal myelogram and vertebral angiogram; abnormal CSF, VEP and $A E P$. There is atrophy of the brainstem, cerebellar vermis, and dilatation of the third ventricle and Sylvian fissures. 

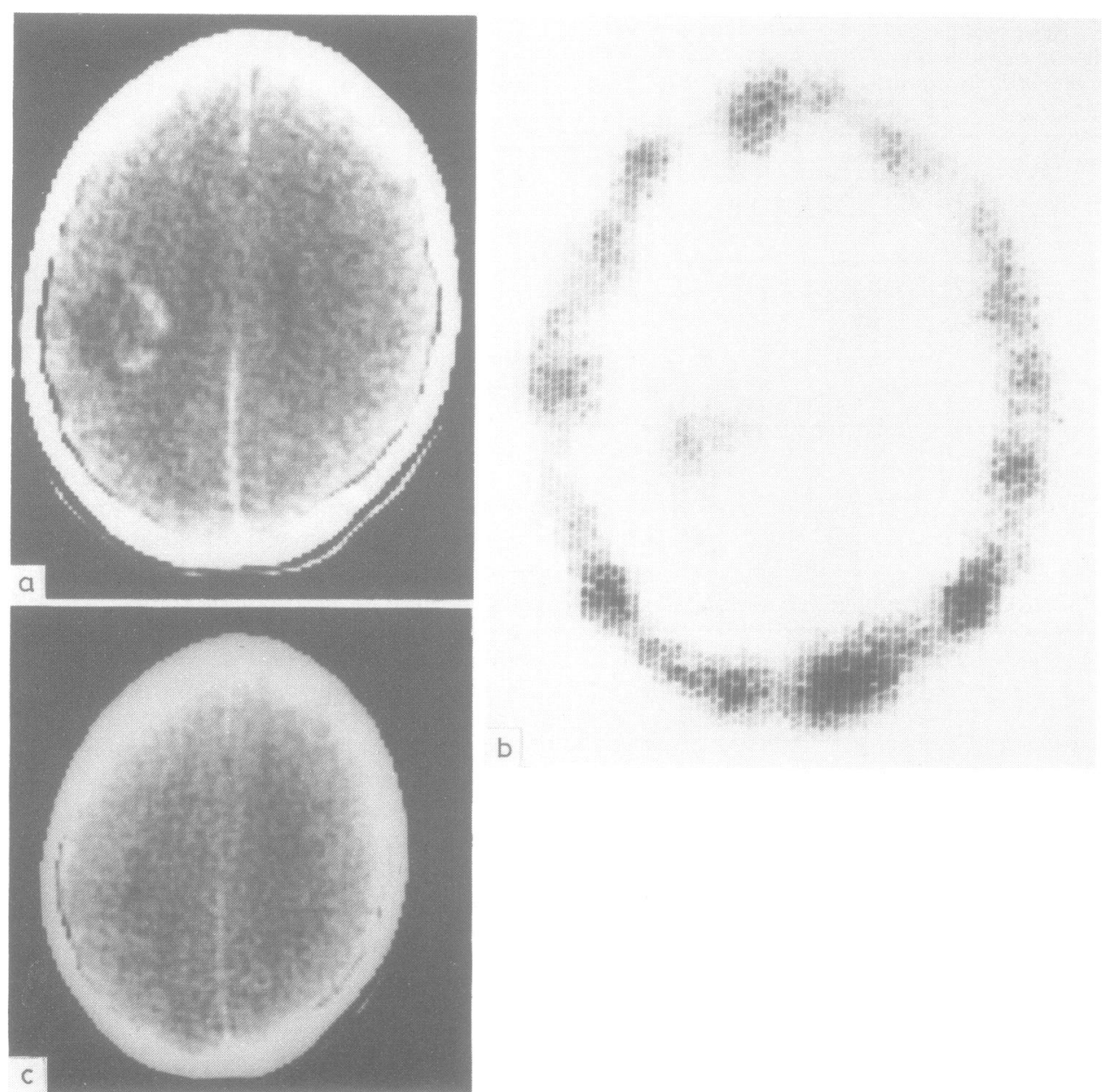

lucencies was $29 \%$, compared with $17 \%$ in patients with no or mild disability; the difference did not reach statistical significance. There was no difference in the incidence of abnormal scans (atrophy \pm lucencies) in these two groups either (table 5). In patients with four to 10 relapses the incidence of lucencies was $41 \%$ compared with $16 \%$ in those with one to three relapses $(p<0.02)$. No lucencies were seen in 32 patients with purely spinal presentation.

\section{Effect of steroids}

Medication with ACTH had been used in 14 patients with definite multiple sclerosis at the time of CT scan. Of these patients, two had normal scans, six showed

Table 5 Disability rating by disease category. (Number of patients with abnormal scans, in brackets)

\begin{tabular}{llrrrr}
\hline Disability & \multicolumn{2}{l}{ Multiple sclerosis category } & Total & $\%$ \\
\cline { 2 - 4 } & $\begin{array}{l}\text { Suspected/ Probable } \\
\text { Possible }\end{array}$ & Definite & & \\
\hline Nil & $9(0)$ & 0 & 0 & 9 & $4 \cdot 5$ \\
Mild & $32(6)$ & $58(26)$ & $47(41)$ & $137(73)$ & $67 \cdot 8$ \\
Moderate & 0 & $22(13)$ & $24(10)$ & $46(23)$ & $22 \cdot 8$ \\
Severe & 0 & 0 & $10(9)$ & $10(9)$ & $4 \cdot 9$ \\
\hline
\end{tabular}


atrophy, and six showed PVL or WML, three of which showed contrast enhancement. The remaining 147 patients in the probable and definite multiple sclerosis categories were not receiving ACTH, and in four of these there was contrast enhancement in white-matter lesions. Thus steroid medication did not alter the detection rate of abnormalities.

\section{Comparison of CT scan with other investigations}

Visual and auditory evoked responses were carried out in just over $50 \%$ of the patients. Abnormal responses were recorded in $66 \%$ of patients with possible multiple sclerosis; in $57 \%$ with probable multiple sclerosis; and in $78 \%$ with definite multiple sclerosis. The CSF was examined in $84 \%$ of all patients; it was abnormal (showing raised cell count, total protein, immunoglobulin or combination of these) in $42 \%$ of patients with suspected, $63 \%$ with probable, and $70 \%$ with definite multiple sclerosis. Statistical analysis showed that both the evoked responses and CSF examination were more sensitive in detecting abnormalities than the CT scan in the possible multiple sclerosis group $(p<0.001$ and $\mathrm{p}<0.02$ respectively), but all three investigations were comparable in the clinically probable and definite groups.

\section{Discussion}

This study has established that the cranial CT features of multiple sclerosis are atrophy, areas of whitematter low attenuation, and areas of abnormal contrast enhancement. It has also provided some epidemiological data on a large hospital group of multiple sclerosis patients. Cerebral atrophic changes, occurring alone or in combination with other lesions, were seen in $44 \%$ of our patients. It was established that the incidence of atrophy is greater in all age groups of multiple sclerosis patients compared with controls; that there is an increase in the incidence of atrophy with advancing disease category; that most atrophic changes occur during the first 10 years of the disease; and that thereafter the increased incidence of atrophy does not reach statistical significance within the multiple sclerosis group. Cala et $a l^{3}$ observed the same positive relationship between atrophy and age, disease duration and category, in their 100 patients, their overall figure for the incidence of atrophy being $44 \%$. Other authors ${ }^{16}$ on the other hand did not find such a correlation, most probably because they confined their studies to patients with long-standing "definite" or "highly probable" multiple sclerosis. The incidence of atrophy as reported in other series ranges between $21 \%$ and $72 \%$, reflecting either the relatively small number of patients studied, or the predominance of patients with definite multiple sclerosis in the series. ${ }^{1569-12}$

Atrophic changes alone were seen in 64 patients in this series, while atrophy in combination with whitematter and periventricular lucencies was present in 25 ; in the latter patients-21 of whom had definite multiple sclerosis, the extent of atrophy was greater, supporting the neuropathological findings of Brownell and Hughes ${ }^{13}$ that there is a close association between ventricular dilatation and the number and size of multiple sclerosis plaques. Infratentorial atrophic changes were found to correlate with clinical data of brainstem or cerebellar dysfunction in a significant proportion of our patients: this is a reflection of the close relationship between structure and function in these areas of the brain, and of their frequent involvement in multiple sclerosis $(68 \%$ of all patients in this series). Cortical atrophy with ventricular dilatation has been reported to correlate with dementia in a small group of multiple sclerosis patients studied by $\mathrm{CT} ;{ }^{5}$ similar observations were made by Barnard and Triggs $^{14}$ in their neuropathological study of 20 multiple sclerosis patients. Such correlation was also seen in the present study, in that all the 14 patients who had dementia or mood changes showed supratentorial atrophy on CT, while no patients with mental changes were found in the group with normal CT scans. In general the presence of atrophic changes is a significant diagnostic observation in patients with a clinical profile suggestive of multiple sclerosis, although such changes are in no way qualitatively different from those found in patients with other disease processes. ${ }^{15-17}$ The discriminant value of atrophy is, however, increased in the presence of white-matter lucencies and areas of contrast enhancement.

In the present series more lucencies were encountered in the central white matter than in the immediate periventricular region (49 vs 15 , in 41 patients). ${ }^{19}$ The white-matter lucencies occurred both as acute symptomatic and as silent lesions, while the periventricular lucencies were all clinically silent. ${ }^{26}$ Lucencies were found mainly in patients with definite multiple sclerosis occurring either alone (16 patients), or in combination with atrophy (25 patients). ${ }^{13618}$ The relatively low incidence of lucencies in the present series may be due to the routine use of $13 \mathrm{~mm}$ or $10 \mathrm{~mm}$ cuts; whereas because of their mainly small size, white-matter lucencies are better seen in $8 \mathrm{~mm}$ or $5 \mathrm{~mm}$ cuts. ${ }^{1319-21}$

Enhancement of the CT scan did not result in demonstration of a substantially greater number of abnormal areas in the white matter. Only seven of 149 patients who were given contrast showed enhancing lesions; in four, the lesions were detectable in the unenhanced scans; in the other three, unenhanced 
scans were not available. Other authors found no enhancing lesions, ${ }^{16}$ or only a few. ${ }^{3591222}$ By contrast, $30 \%$ of patients in a recent study ${ }^{11}$ showed enhancing lesions, and in another study ${ }^{18}$ enhancement was found in 16 low-attenuation and 15 isodense lesions, representing $65 \%$ of all lesions seen in 14 patients with definite or probable multiple sclerosis. Enhancement is thought to be due to leakage of contrast material through a damaged blood brain barrier in multiple sclerosis lesions. ${ }^{181924-28}$ In favour of this view is the observation that such lesions may also show increased uptake of isotope on radionuclide scans ${ }^{29-34}$ as observed in two patients in this series, and in two others subsequently. Such lesions are, however, angiographically negative. They may show easier detection if CT scanning is delayed for about two hours after contrast injection, and if a higher than normal dose of contrast is used. ${ }^{33-36}$ It has been suggested that enhancement is only seen in patients who are in acute exacerbation. ${ }^{924} \mathrm{~A}$ case has been reported, however, with biopsy-proven acute multiple sclerosis, in whom the white-matter lesion did not show contrast enhancement, ${ }^{31}$ and a further case with biopsyproven multiple sclerosis showed enhancement in a lesion, while in clinical and pathological regression. ${ }^{34}$ Some of the patients in this series showed contrast enhancing lesions while stable or in remission. Thus, contrast enhanced CT may not always give an accurate indication of disease activity. ${ }^{37}$ The influence of steroids on contrast enhancement has been rather controversial. It has been suggested that by re-establishing the blood-brain barrier, steroids reduce contrast enhancement in white-matter lesions. ${ }^{1923}$ In the present series, three out of seven patients with enhancing lesions were receiving steroids at the time of scanning.

Enhancing lesions in multiple sclerosis should be differentiated from other pathologies, for example, glioma, metastases, arteriovenous malformation, and infarcts. ${ }^{38}{ }^{39} \mathrm{~A}$ characteristic feature of the lesions in multiple sclerosis is their localisation in the white matter, and their lack of space-occupation (with the notable exception of the one well documented case in the literature $\left.{ }^{40}\right)$. On subsequent examinations, white-matter lucencies may resolve to isodensity, or new ones may appear-a further diagnostic point. ${ }^{38}$

It was noted that the overall mean age at onset of the disease in this series was identical in the two sexes (33. 8 years), but significantly earlier in females in the suspected/possible categories. There was no greater incidence of the disease in females over the age of 40 years, in contrast to the findings of a recent study. ${ }^{41}$ There was a preponderance of females $(63 \cdot 8 \%)$ and in $73 \%$ of patients the onset of the disease was before the age of 40 years: figures comparable with the $60 \%$ and $80 \%$ respectively in the latter study. ${ }^{41}$ The classification of patients according to clinical criteria alone resulted in the relatively lower figure $(39 \%)$ for the definite category compared with the $50 \%$ figure in the French study, ${ }^{41}$ which took into consideration laboratory results. The majority of our patients had no or only mild disability (5\% and $67 \%$ respectively), moderate disability affecting $23 \%$, and severe disability $5 \%$ of patients. The percentage of abnormal scans in these four functional groups was $0 \%, 53 \%$, $50 \%$ and $90 \%$ respectively. It was interesting to note that within the definite multiple sclerosis category there were more abnormal scans in patients with mild disability than in patients with moderate and severe disability combined $(87 \%$ vs $56 \%, \mathrm{p}<0.01)$. At present, therefore, the CT scan can only discriminate between patients with no disability, some disability, and severe disability, but cannot be used reliably as an indicator of prognosis.

Comparison of the standard CT scan with CSF examination and electrophysiological tests showed that the latter investigations were superior in detecting abnormalities in the possible or suspected cases of multiple sclerosis. This is at variance with the results of another study " on 33 patients, 10 of whom had the diagnosis of possible multiple sclerosis supported by CT. In this category, the value of CT scanning lies in the fact that it excludes alternative structural pathology, and may also demonstrate relevant white-matter lesions in individual patients. In patients with probable or definite multiple sclerosis, the CT scan provides as much information as the CSF analysis and electrophysiological tests, but in addition it provides direct evidence of dissemination of lesions in various parts of the neuraxis. ${ }^{6} \mathrm{~A}$ similar conclusion could be drawn from a study of 72 patients with chronic progressive myelopathy investigated by CSF analysis, neurophysiological tests, and CT. ${ }^{42}$

Further improvements in the resolution of CT scanners may make it possible to detect lesions in the brainstem, optic nerves, and spinal cord ${ }^{43}$ with greater accuracy, thus enhancing the value of $\mathrm{CT}$ as a diagnostic tool in multiple sclerosis, though it may be supplanted by nuclear magnetic resonance imaging, when this facility becomes widely available. ${ }^{44}$

We gratefully acknowledge the co-operation of our clinical colleagues at the Midland Centre for Neurosurgery and Neurology and the Queen Elizabeth Hospital, Birmingham. Invaluable secretarial assistance was provided by Miss $S$ Alexander and Miss $M$ Smith; radiographic assistance by Miss E Kirkwood and Mrs R Tyler, and photographic assistance by Mr S Thomas. 


\section{References}

1 Gyldensted C. Computer tomography of the cerebrum in multiple sclerosis. Neuroradiology 1976;12:33-42.

2 Cala LA, Mastaglia FL. Computerised axial tomography in multiple sclerosis. Lancet 1976;1:689.

${ }^{3}$ Cala LA, Mastaglia FL, Black JL. Computerized tomography of brain and optic nerve in multiple sclerosis. J Neurol Sci 1978;36:411-26.

4 Lane B, Carroll BA, Pedley TA. Computerized cranial tomography in cerebral diseases of white matter. Neurology (Minneap) 1978;28:534-44.

5 Hershey LA, Gado MH, Trotter JL. Computerized tomography in the diagnostic evaluation of multiple sclerosis. Ann Neurol 1979;5:32-9.

- Reisner T, Maida E. Computerized tomography in multiple sclerosis. Arch Neurol 1980;37:475-7.

7 Delouvrier JJ, Desbleds MT, Tritschler JL, Aboulker J, Nahum H. Computer tomography changes in multiple sclerosis. J Radiol 1980;61:35-43.

8 McDonald WI, Halliday AM. Diagnosis and classification of multiple sclerosis. Br Med Bull 1977;33:4-9.

9 Wüthrich R, Gigli H, Wiggli U, Müller HR, Elke M, Hünig R. CT scanning in demyelinating diseases. In: Lanksch W, Kazner E, eds, Cranial Computerized Tomography. Berlin: Springer Verlag 1976:239-43.

10 Jacobs L, Kinkel WR. Computerized axial transverse tomography in multiple sclerosis. Neurology (Minneap) 1976;26:390-1.

1 Tritschler JL, Delouvrier JJ, Masson M, Nahum H, Cambier J. Use of cerebral computer tomography for the diagnosis of multiple sclerosis. Rev Neurol (Paris) 1979;135:455-66.

12 Radue EW, Kendall BE. Iodide and xenon enhancement of computed tomography (CT) in multiple sclerosis. Neuroradiology 1978;15:153-8.

${ }^{13}$ Brownell B, Hughes JT. The distribution of plaques in the cerebrum in multiple sclerosis. J Neurol Neurosurg Psychiatry 1962;25:315-20.

14 Barnard RO, Triggs M. Corpus callosum in multiple sclerosis. J Neurol Neurosurg Psychiatry 1974;37: 1259-64.

15 Carlen PL, Wilkinson DA, Wortzman G, et al. Cerebral atrophy and functional deficits in alcoholics without clinically apparent liver disease. Neurology (NY) 1981;31:377-85.

16 Koller WC, Glatt SL, Perlik S, Huckman MS, Fox JH. Cerebellar atrophy demonstrated by computed tomography. Neurology (NY) 1981;31:405-12.

17 Huckman MS, Fox JH, Ramsey RG. Computed tomography in the diagnosis of degenerative diseases of the brain. Seminars in Roentgenology 1977;12: 63-75.

18 Weinstein MA, Lederman RJ, Rothner AD, Duchesneau PM, Norman D. Interval computed tomography in multiple sclerosis. Radiology 1978; 129:689-94.

19 Aita JF, Bennett DR, Anderson RE, Ziter F. Cranial CT appearance of acute multiple sclerosis. Neurology (Minneap) 1978;28:251-5.

${ }^{20}$ Haughton VM, Ho KC, Williams AL, Eldevik OP. CT detection of demyelinated plaques in multiple sclerosis. AJR 1979;132:213-5.

21 Aita JF. Multiple sclerosis and cranial lesions. Arch Neurol 1980;37:738.

22 de Weerd AW. Computerized tomography in patients with multiple sclerosis. Clin Neurol Neurosurg 1977; 80:258-63.

${ }^{23}$ Sears ES, Tindall RSA, Zarnow H. Active multiple sclerosis. Enhanced computerized tomographic imaging of lesions and the effect of corticosteroids. Arch Neurol 1978;35:426-34.

${ }^{24}$ Lebow S, Anderson DC, Mastri A, Larson D. Acute multiple sclerosis with contrast-enhancing plaques. Arch Neurol 1978;35:435-9.

25 Harding AE, Radue EW, Whiteley AM. Contrastenhanced lesions on computerised tomography in multiple sclerosis. J Neurol Neurosurg Psychiatry 1978;41:754-8.

26 Aita JF. Cranial CT and multiple sclerosis: contrast enhancing lesions. Arch Neurol 1978;35:183.

27 Gado MH, Phelps ME, Coleman RE. An extravascular component of contrast enhancement in cranial computed tomography. Radiology 1975;117:589-93.

${ }^{28}$ Gado MH, Phelps ME, Coleman RE. An extravascular component of contrast enhancement in cranial computed tomography. Radiology 1975;117:595-7.

29 Antunes JL, Schlesinger EB, Michelsen WJ. The abnormal brain scan in demyelinating disease. Arch Neurol 1974;30:269-71.

${ }^{30}$ Cohan SL, Formaglich J, Auth TL. Abnormal brain scans in multiple sclerosis. J Neurol Neurosurg Psychiatry 1975;38:120-2.

31 Warren KG, Ball MJ, Paty DW, Banna M. Computer tomography in disseminated sclerosis. Can J Neurol Sci 1976;3:211-6.

${ }^{32}$ Murray S, Veidlinger OF. Serial radionuclide scans in multiple sclerosis. Can J Neurol Sci 1978;5:321-3.

${ }^{33}$ Morariu MA, Wilkins DE, Patel S. Multiple sclerosis and serial computerized tomography. Delayed contrast enhancement of acute and early lesions. Arch Neurol 1980;37:189-90.

${ }^{34}$ Marano GD, Goodwin CA, Ko JP. Atypical contrast enhancement in computerized tomography of demyelinating disease. Arch Neurol 1980;37:523-4.

35 Prendes JL. Contrast dose in CT scanning. Arch Neurol 1981;38:67-8.

${ }^{36}$ Davis JM, Davis KR, Newhouse J, Pfister RC. Expanded high iodine dose in computed cranial tomography: A preliminary report. Radiology 1979; 131:373-80.

${ }^{37}$ Poser CM. Exacerbations, activity and progression in multiple sclerosis. Arch Neurol 1980;37:471-4.

${ }^{38}$ Hyman RA, Blankfein RJ, Pitman ER, Naidich JB, McGeachie RE. Computed tomography: Regression of periventricular enhancing lesions in multiple sclerosis. Comput Tomogr 1979;3:93-6.

39 Britt RH, Connor WS, Enzmann DR. Occult arteriovenous malformation of the brainstem simulating multiple sclerosis. Neurology (NY) 1981; 31:901-3.

40 van der Velden M, Bots GTAM, Endtz LJ. Cranial CT in multiple sclerosis showing a mass effect. Surg Neurol 1979;12:307-10. 
${ }^{41}$ Confavreux C, Aimard G, Devic M. Course and prognosis of multiple sclerosis assessed by the computerized data processing of 349 patients. Brain 1980;103:281-300.

${ }^{42}$ Paty DW, Blume WT, Brown WF, Jaatoul N, Kertesz A, McInnis W. Chronic progressive myelopathy: Investigation with CSF electrophoresis, evoked potentials and CT scan. Ann Neurol 1979;6:419-24.

${ }^{43}$ Coin CG, Hucks-Folliss A. Cervical computed tomography in multiple sclerosis with spinal cord involvement. J Comput Assist Tomogr 1979;3:421-2.

${ }^{44}$ Young IR, Hall AS, Pallis CA, Bydder GM, Legg NJ, Steiner RE. Nuclear magnetic resonance of the brain in multiple sclerosis. Lancet 1981;2:1063-6. 